\section{A science-oriented search engine could solve web problems ...}

Sir-Lawrence and Giles eloquently describe the problems with the WorldWide Web - the small percentage of total pages indexed by search engines and their bias towards 'popular' pages (Nature 400, 107-109; 1999). This suggests that a large proportion of the scientific information on the web, from home pages to preprints and sequences, may never be discovered. But the authors also point to a way forward.

Only six per cent of web servers have scientific or educational content - a much more manageable amount to index. Metadata (information about information) is the key to better searching, yet only 0.3 per cent of servers use the Dublin Core standard for metadata: http://purl.org/dc/. We need a science-oriented search engine, together with a set of scientific metadata, to help us trawl the oceans of information.

I think that a hybrid indexing scheme, halfway between the formidable task of a human-generated Internet catalogue like Yahoo! and the huge computer-generated indexes like AltaVista, is the way forward. Submission of an institution's home page would, after manual verification to exclude inappropriate sites, lead to the computerized indexing of the rest of the site.

The next step is for the scientific community to discuss suitable extensions to the Dublin Core metadata to describe the rich variety of scientific information available on the web. Nature's debates - at http://helix.nature.com/debates — would seem to be the ideal forum.

Mike Gardner

School of Biomedical Sciences, University of

Nottingham, Queens Medical Centre,

Nottingham NG7 2UH, UK

\section{... just try to be specific ...}

Sir - It is disturbing that no single search engine indexes more than a meagre 16 per cent of the web, down from about 33 per cent 18 months ago (Nature 400, 107-109; 1999). Users' ability to look at documents has remained static, so people still only look at the first few tens of search results.

Most mainstream search engines rely on relevance-score algorithms to rank matches. Such algorithms are prone to manipulation by content providers, who can rig their content to yield a spuriously high relevance score. But transparent algorithms are necessary for users to understand how to get the most from search engines. The end result is a long list of hits of doubtful relevance, quality and completeness.
This makes topic-specific search engines - which aim to cover the majority of content within a specific topic, rather than a small fraction of every topic - all the more appealing. Such an approach also allows content to be reviewed and structured so that users are presented with an intelligently categorized, hierarchical list of matches, rather than a linear one. This allows rapid identification ('drilling down') of the most relevant matches.

One example that addresses these issues is OrthoSearch (www.orthosearch.com), covering orthopaedics and related topics. OrthoSearch uses the Internet Society of Orthopaedic Surgery's web-links policy to determine which sites are relevant, avoiding many shortcomings of the most popular search engines.

A. L. S. Chiu ${ }^{\star}$, E. Sherry $\dagger$, X. Phung $\$$

${ }^{*}$ Department of Anatomy and Histology,

tDepartment of Orthopaedic Surgery,

§Westmead Hospital, The University of Sydney,

New South Wales 2750, Australia

\section{using peer review as a guide to quality}

Sir-A statement often attributed to the late science fiction editor John W. Campbell says: "90 per cent of science fiction, indeed 90 per cent of anything, is garbage". With this in mind, the recent report that Internet search engines index only an average of 7-16 per cent of the web becomes much less alarming (Nature 400, 107-109; 1999).

Most Nature readers will agree that Campbell's law is eminently applicable to the Internet. The pressing concern is not what percentage of the web a search engine covers, but how much of the web is worthy of coverage and how to identify that fraction. The scientific community has long had a mechanism to categorize information worthy of attention: peerreviewed publication. So, if one needs useful information on, say, nerve growth factor, PubMed is likely to be a more useful website than the Yahoo! search engine. One hopes that the architects of the 'E-Biomed/ E-Biosci' initiative bear this in mind.

\section{Mike Fainzilber}

Molecular Neurobiology Group, Department of

Biological Chemistry, Ullman Building, Weizmann Institute of Science, 76100 Rehovot, Israel

\section{Money, money, money}

Sir - Vasiliki Plerou et al. suggest that the similarities between the growth dynamics of university research and of businesses may be due to the similarity of peer review and government direction to market forces, that is, consumer evaluation and product regulation (Nature 400, 433-437; 1999).
I can think of another possible cause: that the goal of universities has now become similar to the goal of businesses - to make money.

Barbara-Ann G. Lewis

Department of Civil Engineering, Northwestern

University, Evanston, Illinois 60202, USA

\section{Will Explore set the next century's standards?}

Sir - Heather McCabe's news article "UK centre drops science for sensation" (Nature 400, 804; 1999) gives a false impression of Explore at Bristol, and of the relationship between Explore and the Exploratory.

Explore is part of a $£ 97$ million millennium project in the centre of Bristol. In seeking to widen the appeal of science, nature and the arts, two new centres (Explore at Bristol and Wildscreen at Bristol) and a public art programme in the new squares and walkways are being created. Explore at Bristol focuses on people, their brains and how these affect the way they see the world, their dreams for technology, their place in evolution and their impact on the planet. The centre is covering new subject areas and widening the range of media used. But it is most certainly building on its inheritance from the Exploratory, and a 'hands-on' approach is at its heart.

Many of the Exploratory exhibits will be used, with one-third of Explore at Bristol exhibits being the same as Exploratory exhibits; more than twothirds of all the exhibits in Explore will be hands-on. Professor Richard Gregory was the first to introduce hands-on science to the United Kingdom in Bristol about 16 years ago. We believe we are building on this concept and extending it to an even broader public.

Hands-on science is most effective for eighteenth- and nineteenth-century science and fundamental phenomena: light, electricity, magnetism, and so on. For many newer areas such as life and biomedical sciences, or different aspects such as the social implications of science, different techniques are needed. We want the best method for communicating messages and encouraging people to explore the world around them. Exhibits will be grouped in themes and the handson approach reinforced by other types of experience and information.

Two nominees of the Exploratory Trust have been on the board of Explore at Bristol since 1995; Gregory, who founded the Exploratory, is chairman of the science advisory panel for Explore at Bristol and an honorary life vice-president. Gregory himself said of Explore recently, on BBC Radio Bristol's John Turner Programme, 
"They are actually using a lot of our exhibits and no doubt will develop and improve them because they've got more facilities. From the point of view of Bristol ... I think actually there may be a gain."

Just as the Exploratory set new standards when it opened, so Explore at Bristol is striving to set new standards for the next century. We hope readers will come and see for themselves when we open - on time, and on budget - next spring.

Gillian Thomas

Chief Executive, at-Bristol, Deanery Road,

Harbourside, Bristol BS1 5DB, UK

McCabe replies - My article correctly reports the relationship between Explore and the Exploratory. But, as chief executive of at-Bristol, Gillian Thomas naturally does not agree with the criticisms I reported of Explore's approach to science.

Although Thomas says that Explore is carrying on the tradition of the Exploratory, many scientists involved in planning the new centre believe that the scientific content of Explore is thin. Thomas and her colleagues pointed out to me examples such as brains you can touch, crickets you can look at through a magnifying glass, and a virtual-reality sperm ride. Although these are hands-on in a literal sense, they do not oblige visitors to run through a miniexperiment to observe a scientific principle.

The scientists I spoke to embrace the idea of having a centre with a wider appeal and a budget to build more modern exhibits, as Thomas stresses that Explore is doing. Yet they say that, in the rush to open in a timely fashion for the millennium, Explore is creating expensive exhibits that favour special effects over scientific substance.

\section{Spanish recruitment openly favours insiders}

Sir - Rigidity and cronyism characterize hiring practices for academic positions in Spain (Nature 396, 709; 1998). This happens both in universities, as denounced in your pages, and, to a lesser extent, in the Spanish Research Council (CSIC), the country's largest research body. This is demonstrated by two worrying developments during the past few months.

First, in order to 'stabilize' the situation of university lecturers on short-term and irregular contracts, the government and university vice-chancellors have proposed promoting 10,000 of them to permanent lecturer positions. This highly irregular upgrade is, however, closed to equally qualified postdocs in non-university research institutes (such as CSIC) or abroad. It would result in a freeze on university hiring for the foreseeable future, leaving non-university centres and foreign countries as the only outlets for researchers seeking tenure-track academic jobs.

Second, CSIC has announced 90 new research positions, for which candidates are assessed on a score of up to 20 (Nature 399, $400 ; 1999)$. Ten points have to be earned on merit (including publications and experience) to reach the final selection process. But five points are given as a 'prize' to people who have worked in CSIC putting other candidates at a clear disadvantage as they can only obtain a maximum of 15 points.

Job openings at CSIC and universities are not widely advertised, and bureaucratic requirements make them almost unattainable by outside candidates (Nature 400, 203; 1999). For example, the 90 CSIC posts were only advertised in the Spanish Official Bulletin - an obscure government publication that is not widely available and on the CSIC website. Applications typically have to be in within two weeks. Foreign qualifications require government 'validation', a process that can drag on for up to a year, discouraging candidates applying from outside Spain.

The solution to this cronyism is readily at hand. CSIC, universities and the Spanish government should simply follow the hiring policy of Spain's National Centre for Cancer Research, which is also common practice in Britain and the United States: job advertisements should appear in scientific journals, with plenty of time to apply, in order to attract the best candidates. The government should also remove bureaucratic obstacles that prevent outside scientists being hired.

Other problems exist in Spanish science, including 0.8 per cent of GNP dedicated to research (against a European average of 2.1 per cent), and a lack of research facilities and positions. But before solving those it is necessary to eradicate cronyism. This is one of the goals of the Association for the Advancement of Science and Technology in Spain (AACTE: http://www. aacte.net). It is the only way to attract good researchers, provide a healthy and flexible science base and high-quality education, and have a commitment to excellence in science. Javier Escartin

IJA-CSIC, Martí Franqués s/ $n$, 08028 Barcelona, Spain and 23 others

\section{New opportunities for expert witnesses in court}

Sir - Many scientists are required to give expert witness in civil litigation. Recent, sweeping reforms to English civil justice have radically changed the way scientists give their evidence. The agenda and rules of the courtroom have changed, and this may provide new opportunities for scientific evidence to influence legal disputes. In particular the introduction of a single court expert, to replace the cross-examining of different parties' experts, will open new areas for scientists to use their expertise.

Civil law provides the basic structure within which commerce and industry operate, and safeguards the rights of individuals. In 1994, Lord Woolf was appointed to review the civil courts in England and Wales ${ }^{1}$, resulting in the new Civil Procedure Rules (CPR) ${ }^{2}$.

In English law, witnesses do not usually testify to anything but facts. However, the courts recognized the need for special witnesses providing evidence on both fact and opinion. The duties of expert witnesses evolved and were reinforced by case law $^{3}$.

Although, in principle, the expert is independent of the instructing party, the system had flaws. These have been addressed in the Woolf review by introduction of new CPR, practice directions and forms. The new CPR came into force on 26 April 1999, and apply to all civil courts in England and Wales.

One key aspect of the changes is the duty of the expert to help the court, overriding any obligation to the person who instructs, or pays, the expert (CPR Part 35.3). The expert must include verification of the contents of any report with a statement of truth (CPR Part 35.10).

The court has a duty - not merely the power - to restrict expert evidence (CPR Part 35.1), and there is now a general requirement for expert evidence to be given in writing, removing many of the criticisms of the system resulting from adversarial cross-examination. Oral evidence and the attendance of experts at hearings will be restricted (CPR Part 35.5).

The changes to the civil justice system are as much cultural as procedural. All parties must be ready to be proactive, and must see this as the beginning, not the end, of the process of change.

The debate on the efficacy of expert witnesses appointed by the parties in dispute has raged elsewhere, notably in the United States in the late 1980s (Nature 378, 754 ; 1995). Litigation should be the last, not the first, resort in attempts to settle a dispute, and this principle is central to the Woolf reforms. Experts now have greater scope to both affect and effect settlement.

Peter Fenn ${ }^{\star}$, Christine Jinks *, Michael O'Shea $\dagger$

${ }^{\star}$ Department of Building Engineering, UMIST, PO Box 88, Manchester M60 1QD, UK

$\dagger$ Masons Solicitors and Privy Council Agents, 100 Barbirolli Square, Manchester M2 3SS, UK

\footnotetext{
1. Lord Woolf Access to Justice (Woolf enquiry team, Room 438, Southside, 105 Victoria St, London SW1E 6QT, UK; 1995). 2. Civil Procedure Rules (The Stationery Office, London, 1999). 3. National Justice Compania Naviera S. A.v Prudential Assurance Company Limited (The Ikarian Reefer) CILL 838 (1993).
} 